\title{
Professional development of code and robotics teachers through Small Private Online Course (SPOC): Teacher centrality and pedagogical strategies for developing computational thinking of students
}

\author{
Shlomit Hadad ${ }^{1}$ \\ Tamar Shamir-Inbal ${ }^{2}$ \\ Ina Blau ${ }^{3}$ \\ Eynat Leykin ${ }^{4}$
}

Corresponding Author: Ina Blau, Department of Education and Psychology, The Open University of Israel, 1 University Road, P.O.B. 808 Ra'anana 43107, Israel.

Email: inabl@openu.ac.il

This is the pre-peer reviewed version of the following article:

Hadad, S., Shamir-Inbal, T., Blau, I., \& Leykin, E. (2021). Professional Development of Code and Robotics Teachers Through Small Private Online Course (SPOC): Teacher Centrality and Pedagogical Strategies for Developing Computational Thinking of Students. Journal of Educational Computing Research, 59(4), 763-791.

Which has been published in final form at https://doi.org/10.1177\%2F0735633120973432.

This article may be used for non-commercial purposes and no derivative uses in accordance with SAGE Terms and Conditions for Use of Self-Archived Versions.

\footnotetext{
${ }^{1}$ Department of Information Science, Bar-Ilan University, Ramat Gan, Israel

${ }^{2}$ Department of Education and Psychology, The Open University of Israel, Ra'anana, Israel

${ }^{3}$ Department of Education and Psychology, The Open University of Israel, Ra'anana, Israel

${ }^{4}$ Israeli Ministry of Education, Yerushalayim, Israel
} 


\begin{abstract}
This study explored (1) pedagogical strategies in Educational Coding and Robotics (ECR) learning which can develop computational thinking of students and (2) the degree of teacher centrality in the ECR classroom. In addition, we investigated (3) the added value of the Small Private Online Course (SPOC) to teacher professional development (TPD). We analyzed reflections of 80 in-service teachers on TPD through the SPOC (1,091 statements) and conducted semi-structured interviews with 13 of them one year after completing the course and teaching ECR in the classroom (328 statements). The most prominent strategies immediately after the TPD were constructing learning experiences, tinkering \& debugging, and interdisciplinary learning, while one year later, experiential learning and collaborative learning were more common. Regarding the degree of teacher centrality, a year after teaching ECR curriculum the teachers had a significantly higher percentage of statements reflecting their role as a guide-on-the-side and as a partner of students in the learning process. Regarding the contribution of the SPOC for TPD, teacher statements revealed significantly more benefits than challenges in both points of time. Interestingly, the same categories emerged bottom-up as benefits and challenges: a variety of control dimensions, independent learning, learning and knowledge management and collaboration. Implications for educational theory and ECR practice are discussed.
\end{abstract}

Keywords: Educational Code and Robotics (ECR), pedagogical strategies, computational thinking, teacher centrality in the classroom, Teacher Professional Development, Small Private Online Course SPOC. 


\section{Introduction}

Professionals in the knowledge society need digital skills suitable for coping with constantly evolving information and communication technologies (ICT), digital tools, and applications (Zviel-Girshin, Luria \& Shaham, 2020). Nowadays programming has been accepted as a "new literacy" for active online participation (García-Peñalvo, Reimann, Tuul, Rees, \& Jormanainen, 2016) and one of the important competencies for success in digital environments (Baek et al., 2019). Educational Coding and Robotics (ECR) has been argued to foster not only STEM (science, technology, engineering, and mathematics), but also to promote general skills, such as creativity, collaboration, problem-solving, and self-expression, and to improve student characteristics, such as motivation and self-confidence (Blau \& Benolol, 2016; Chen, Park \& Breazeal, 2020; Scherer, Siddiq, \& Sánchez Viveros, 2018; Zviel-Girshin, 2020).

Computational thinking (CT) is defined as "an approach to solving problems, designing systems, and understanding human behavior that draws on concepts fundamental to computing" (Wing, 2008, p. 3717). CT has been recognized as an essential skill in the digital age and a core element of teaching coding (Hsu, Chang, \& Hung, 2018). The importance of studying CT and programming as an integral part of the curriculum in primary and secondary schools has been recognized by a variety of countries and governments (Hsu et al., 2018; Mason \& Rich, 2019).

However, a successful approach to ECR requires appropriate pedagogy, classroom settings, and teaching methods (Cengel, Alkan \& Cayir, 2018; García-Peñalvo et al., 2016). Research literature regarding teacher training for ECR is scarce, especially in elementary (K-6) education (Mason \& Rich, 2019). Furthermore, studies found that teachers who were not properly trained lacked the self-confidence needed to teach ECR (Mason \& Rich, 2019; Rich, Jones, Belikov, Yoshikawa, \& Perkins, 2017; Sentance \& Csizmadia, 2015). Cengel and colleagues (2018) suggested that abundant training for ECR should be offered because of the high demand. One of the solutions for this demand for geographically dispersed training is to design an online course for distance training, which would allow, on the one hand, some flexibility of time and space and, on the other hand, would enhance self-regulated learning skills of the trainees (Marcelino et al., 2018).

While online distance learning has already been established in higher education, vocational training, and personal development, it is likely that the importance of Massive Open Online 
Courses (MOOCs) and Small Private Online Courses (SPOCs) for professional development will increase even further (Kaplan \& Haenlein, 2016). Recently, distance learning has been shown to be essential for both teachers and students because of workloads or situations such as the COVID-19 pandemic. Nevertheless, most of the previous studies relate to students in higher education and vocational training (e.g. Kaplan \& Haenlein, 2016; Tang et al., 2019; Wang et al., 2016), while very few studies (e.g., Kappas \& Tsolis, 2018) examine the effectiveness and contribution of these online courses for training teachers.

The aims of this study were to explore pedagogical strategies prevalent in ECR and to understand the degree of teacher centrality in the ECR classroom. In addition, the study explored the added value of the SPOC (Small Private Online Course) for professional training of ECR teachers.

\section{Literature review}

This paper embraces two theoretical approach. The computational thinking approach is relevant to the topic of this TPD and the new code curriculum in the schools. The teacher prototype framework is relevant to exploring the degree of teacher centrality in the a ECR classroom after training in a SPOC, which was characterized by student-centered learning pedagogical approach rather than by teacher-centered instruction.

\section{Strategies to promote computational thinking through coding and robotics}

Learning programing is a working paradigm that contributes to students' ability to solve problems and develop computational thinking (Chen et al., 2017). Computational thinking is a focused approach to problem-solving, incorporating thought processes that utilize abstraction, decomposition, algorithmic design, evaluation, and generalizations (Selby \& Woollard, 2013). Kalelioglu, Gulbahar and Kukul (2016) conducted a literature review to propose a definition based on elements that are widely accepted. Abstraction, algorithmic thinking, problem solving, pattern recognition, and design-based thinking were the top five elements underlined by researchers' definitions.

Teaching and learning CT skills can be promoted through diverse teaching methods ranging from step-by-step demonstrations and explanations, in which teachers lead the educative process, to project-based explorative inquiries (Baek et al., 2019). CT ideas can advance students from being merely technology-literate to using computational methods for solving 
complex problems and presenting knowledge (Yadav, Hong \& Stephenson, 2016). In their review, Hsu and colleagues (2018) found that educators adopt different learning strategies to help students improve their CT. They discovered that most research focused on project-oriented learning, problem-oriented learning, cooperative learning, game-based learning, systematic computational strategies, scaffolding strategies, storytelling learning, and aesthetic experience. Baek and colleagues (2019) revealed several groups of strategies in teaching CT skills, starting with simple strategies, such as understanding or using modifying-creating instruction, up to strategies of manipulating embodied objects, reflecting on mistakes, and creating a story and narration (Baek et al., 2019).

In order to develop computational thinking of students, teachers need to employ various strategies, rather than rely on one particular strategy. They need to modify lessons in order to adequately teach the domains according to the challenge level and the age of the child (Bech et al., 2019; Hsu et al., 2018; Mason \& Rich, 2019). A survey of ICT teachers showed that those teachers who were confident in their ability to teach coding were combining strategies around code exercises, using discussion, collaboration and peer learning, and CT strategies (Sentance \& Csizmadia, 2015). It is recommended that educators try different strategies to match ECR student needs (Zviel-Girshin et al., 2020). Modification of these strategies needs to be conducted based on the assessment of students' CT skills (Denning, 2017; Tozadore \& Romero, 2020).

\section{Teacher prototypes as reflected in their pedagogy in ECR}

ECR supports collaboration and teamwork, creativity and imagination, critical thinking and problem-solving skills, and enhances children's self-confidence in their abilities (Chen et al., 2020; Zviel-Girshin et al., 2020). In order to enable students to develop these skills, teachers cannot just ask students to copy their code, which limits students' thinking and learning processes (Denning, 2017). Instead, teachers should adjust to a new kind of classroom setting and choose teaching methods appropriate to the ECR curriculum (Cengel el al., 2018; GarcíaPeñalvo et al., 2016; Hsu et al., 2018).

Teachers are the pedagogical agents in the classroom and their beliefs about their role in the classroom match their performance and their teaching methods (Heitink et al., 2016). They differ in their degree of centrality in the classroom, demonstrate teaching styles associated with particular roles, attitudes, and pedagogical strategies, and play a vital role in the students' ability 
to learn (Grasha \& Yangarber-Hicks, 2000; Yondler, Blau, Ben-Yehudah \& Eshet-Alkalai, 2018). A well-established framework of teaching styles suggested by Grasha and YangarberHicks (2000) describes four teacher styles of technology integration in the classroom: the teacher as an expert/formal authority, the teacher as a personal model, the teacher as facilitator, and the teacher as delegator. Yondler and colleagues (2018) added to the teachers' styles taxonomy a prototype of the teacher as a partner, which is absent in Gransha's model and essential for technology-enhanced learning in general and especially for constructionist learning in digital environments such as in ECR. Their prototypes of teachers in technologyenhanced learning environments reflect different degrees of teacher centrality in the classroom (Blau, Shamir-Inbal, \& Malka, 2019; Yondler et al., 2018): (1) a sage-on-the-stage, (2) a facilitator, (3) a guide-on-the-side, and finally (4) a partner. These models revealed the scope of skills that addressed the method of teaching these skills and the features of practices that promote digital literacy skills (e.g. student participation, collaboration, interpersonal interactions and assessment for learning).

In the current study, we integrate Grasha and Yangarber-Hicks' (2000) framework with Yondler and colleagues' (2018) prototypes of teachers in a technology-enhanced environment. Namely, Sage-on-the-stage in Yondler and colleagues' (2018) framework includes Expert, Formal authority and Personal model types in Grasha's framework. Facilitator type is presented in both models. Guide-on-the-side in Yondler et al.'s approach corresponds to Delegator type in Grasha's model. Importantly, a Partner prototype, which is absent in Gransha's model, was added by Yondler and colleagues and highlights the essence of constructionist learning in digital environments. Regarding the partner prototype, Chen et al. (2020) explored teaching ECR with three types of digital pedagogical agents: a tutor who instructs students, a tutee who learns from the students, or as a peer who switches between tutor/tutee roles to support children's cognitive and emotional needs. The peer agent was found to be the most effective agent for children's learning and needs.

\section{Professional development of code and robotics teachers through SPOC}

Effective teacher training is a key component in both the knowledge and the self-confidence of teachers for teaching ECR (Scaradozzi, 2019). Researchers found that teachers who were not properly trained lack the self-confidence needed to successfully teach programming (Mason \& Rich, 2019; Rich, et al., 2017; Sentance \& Csizmadia, 2015). In order to achieve 
the goal of CT for all, it is important to provide professional development opportunities in relation to curriculum needs (Gabriele et al., 2019; Yadav et al., 2016).

Following recognition of the importance of developing programming literacy, CT has become a part of the curriculum in primary and secondary schools (Hsu et al., 2018; Mason \& Rich, 2019). Following many countries, in Israel CT training was set up as one of the national teaching goals (MoE CEO's circular, 2016). Hence, developing teachers' understanding of CT and highlighting its integration in their curricular context is crucial to successful implementation of CT in K-12 classrooms (Gabriele et al., 2019; Yadavet al., 2016). Because of the high demand for teacher professional development (TPD) for ECR, one of the solutions is to design online courses for distance training. Marcelino and colleagues (2018) note that online training allows both flexibility and enhancement of self-regulated learning skills of the trainee. Moreover, they found that it is possible to effectively learn and teach distance CT through a visual programming environment (Scratch in Marceline et al., 2018 study).

Professional development conducted through an online course, such as MOOC or a SPOC, requires self-regulated learning skills. A SPOC is a small online course which, in contrast to MOOC, has a limited number of participants and thus requires some form of formal enrollment (Kaplan \& Haenlein, 2016). In order to change teaching-learning-assessment processes, foster independent learning, and encourage tinkering among their students, teachers need to experience self-directed learning themselves during their training (Koukis \& Jimoyiannis, 2019). A SPOC, as an e-learning course with clear organization of the content, makes it easier for students to learn. The SPOC teaching model uses rich visual and auditory effects to show the teaching content, in contrast to traditional inculcation teaching. Learning through a SPOC can greatly enhance learners' attention, inspire their creative thinking, and, in addition, promote independent and collaborative learning (Fu, 2019). Toikkanen and Leinonen (2017) trained over 500 Finnish primary school teachers of ECR through an online course which participants considered extremely successful. The participants of the Finnish SPOC were confident that the course prepared them to face the challenges of teaching new ECR curriculum.

\section{Research Goals and Questions}

While relatively many studies explore how to teach code in the context of formal education, very few focus on teacher professional development through a SPOC. Moreover, this study aims to understand the added value of the SPOC for ECR teachers immediately after the TPD 
course and after a year of experience in teaching ECR in the classroom. In addition, this study explores application of the SPOC pedagogy, aiming to understand which teaching strategies promote CT in ECR learning and what the degree of teacher centrality is in the ECR classroom.

The research questions explored in this study were:

RQ 1: Which teaching strategies promote code and robotics learning - immediately after the teacher training and after a year of teaching ECR in the classroom?

RQ2: What is the degree of teacher centrality in the classroom in teaching ECR - immediately after the training and after a year of teaching experience?

RQ3: What is the added value of a SPOC for distance teacher training - according to the participants' perspectives immediately after the training and after a year of teaching?

\section{Method}

The study was conducted within the mixed-method research paradigm in which qualitative data is coded and quantitatively analyzed. It examines reflections of 80 code and robotics teachers describing their professional training through SPOCs and conducts semi-structured interviews with 13 of them one year after completing the course.

\section{Participants and Context}

The teachers participated in professional code and robotics online TPD training through a Small Private Online Course (SPOC) platform. The training followed a new code and robotics curriculum initiated by the Israeli Ministry of Education, which uses an open visual programming platform - Scratch - to teach intuitive coding and building 3D programming artifacts (MoE CEO's circular, 2016). Scratch is a block-based visual programming language and online platform with children as the primary target audience. Users of the website can create online projects using a block-like interface. According to the Ministry of Education (MoE CEO's circular, 2016), the purpose behind the code and robotics program is to develop students' computational thinking, which enables problem-solving through trial and error, abstraction, algorithmic thinking, decomposition, pattern recognition, and design-based thinking.

The aim of the SPOC was to provide teachers with key information, tools, and new approaches and techniques for teaching ECR in the classroom. The course not only allowed 
them to understand the basic concepts of coding and robotics, but also combined theoretical training with hands-on components, encouraging active participation of the trainees. The course included 60 hours divided into 30 hours of coding and 30 hours of educational robotics, with the same teachers. There were two assignments during the course, design an educational game in the Scratch environment in pairs and programming a robot in order to activate its basic movements. In addition, two final assignments required the trainees to design their own module for code and robotics and plan a student assignment for each of them. These teaching activities can be accessed by the rest of the learning group and can serve as a shared database of learning activities, which can be used later in the classroom.

Regarding the medium, approximately $25 \%$ of the course was conducted synchronously mostly online, with a few face-to-face meetings. The face-to-face meetings enabled robotics practice, while most of the course was conducted asynchronously. In addition, the trainees reflected on their knowledge and skills and collaborated with colleagues in the course learning community. They provided clarifications and supported each other in the accomplishment of the course activities.

The participants were 80 elementary school in-service teachers, who finished professional code and robotics TPD training through the SPOC described above. At the end of the course these teachers were asked to reflect on various issues related to their training, as detailed in the next section. The teachers had diverse backgrounds and, in addition to ECR, taught language arts, math, and science, or served as ICT coordinators in their school. Since this ECR is a new curriculum, participants' seniority in teaching ECR was very low (0-3 years). Sixty-one (76\%) of the teachers were from Hebrew-speaking schools and 19 (24\%) from Arabic-speaking schools. Two third of the teachers were women, which is consistent with their prevalence in the Israeli education system, especially in elementary education.

In addition, semi-structured interviews were conducted with 13 of these teachers one year after completing the course. Nine $(70 \%)$ of the interviewees were from Hebrew-speaking schools and six (30\%) from Arabic-speaking schools. 54\% of the interviewees were women.

\section{Instruments and Procedure}

\section{Reflections}

At the end of the course participants were asked to fill in a reflection form to describe their feelings and thoughts about the learning process in the course. Reflection is a meaning-making 
process that moves learners from one experience into another with deeper understanding of their practices and their connections to other experiences and ideas (Oliver, Serovich \& Mason, 2005; Rodgers, 2002). The reflection method used in this study refers to the ability of thinking post-factum about one's practice in order to assess and improve this practice (Oliver, Serovich \& Mason, 2005).

Reflections in the current study focused on the teacher's role and the learner's insights on the pedagogical design that encourages tinkering. Teachers were asked to address the four following issues of the ECR training:

1. To describe their feelings about the changes in the role of the teacher and the role of the learner in ECR curriculum.

2. To describe their perspectives on integrating CT concepts in ECR curriculum with a Scratch visual programming environment.

3. To reflect to what extent this type of learning suited them, what the benefits were, and which challenges they experienced after self-directed learning in a SPOC during the TPD.

4. To describe the main ideas and concepts learned through programming and building robots and to provide an example of the way to integrate one of these ideas in the classroom.

The answers were collected through the Google Form application, analyzed "bottom-up", and categorized using a thematic analysis technique. The unit of analysis in this study was a statement presenting a content unit (rather than an individual trainee). These reflections yielded 1,091 codes. The coding was not exclusive, meaning that each statement could be attributed to several categories. To assure inter-rater reliability, $25 \%$ of the reflection statements were analyzed by a second rater and the agreement level was high, Cohen's Kappa $\kappa=.87$.

\section{Interviews}

Thirteen semi-structured interviews were conducted in the second phase of the study a year after the TPD course in order to enable deeper understanding of the meaning the participants attributed to the described phenomena (Kvale, 1983). During the year after the training, all the interviewees taught code and robotics. Conducting interviews a year later provided a view of the application of the TPD course in the interviewees' classroom, as well as their perspectives on the roles of teacher and learner in the ECR curriculum. The interviews were conducted via 
phone by one of the authors, lasted between half an hour and 50 minutes and were based on the interview protocol developed by all the authors.

The interviews focused on the actual pedagogical processes that the teachers carried out in their classrooms. Participants were asked to describe the teaching strategies they used, provide examples of effective strategies, and explain why they were successful. They provided an example of a strategy that did not work in the classroom, explained why, and described how they could overcome the problem. In addition, teachers were asked to characterize learning processes and the role of teacher in ECR curriculum and explain to what extent they were similar/different from learning processes in other subjects they teach in the schools. Finally, the interviewees were asked about skills that their students developed in the ECR classroom and about the skills they developed in the SPOC.

The answers were analyzed "bottom-up" and yielded 328 codes. The analysis was conducted on the level of statements representing a content unit (rather than on the level of the interviewee). The coding of the interview data was not exclusive. Inter-rater reliability for $25 \%$ of the interviewees' statements analyzed by two raters was high, Cohen's Kappa $\kappa=.87$.

\section{Rigor}

In order to ensure reliability in the findings, rigor in both reflections and interviews was based on "trustworthiness of data" (Lincoln \& Guba, 1985). Trustworthiness was assured by adhering to four principles: 1 . truth-value of data: The teachers were informed in advance that their perspectives and reports would be confidential. 2. applicability of the data: We selected teachers from geographically dispersed schools, from different types (city versus rural) of schools, sectors (Hebrew-speaking and Arabic-speaking schools), and different professional backgrounds. 3. Consistency of the data was assured by transcribed verbatim of the interviews and keeping records of data collection. 4. neutrality of the data: We recorded all steps during data coding of the interviews and tried to present teachers' points of view on the phenomenon.

\section{Findings}

\section{Teaching strategies for code and robotics}

The data revealed a variety of teaching strategies for ECR classrooms, both in teacher reflections immediately after the SPOC and in the interviews conducted one year after teaching 
the new curriculum. Table 1 presents shared categories which emerged in both measurements, while Table 2 includes distinct categories found in reflections or interviews. A chi-square goodness of fit test, which compared the observed sample distribution with the expected probability distribution based on the proportion of statements in each theme in the shared categories, was statistically significant, $X^{2}(6)=175.97, p=.000$. The discrepancy between the observed and expected frequencies is used to determine which cells within the contingency table generate residual scores that are larger in magnitude than might be expected by chance (see Agresti, 2018; Sharpe, 2015). The standardized residual presented in Table 1 shows the degree to which an observed chi-square cell frequency differs from the value expected in the interviews based on the reflections data. 
Table 1. Teaching strategies for code and robotics found in both reflections and interviews

\begin{tabular}{|c|c|c|c|c|c|}
\hline & \multicolumn{2}{|r|}{$\begin{array}{l}\text { Reflections after the training } \\
\text { course }\end{array}$} & \multicolumn{2}{|r|}{ Interviews one year later } & $\begin{array}{l}\text { Standardized } \\
\text { residual }\end{array}$ \\
\hline & $\begin{array}{c}\text { Codes } \\
(\%)\end{array}$ & Representative citations & $\begin{array}{c}\text { Codes } \\
(\%)\end{array}$ & Representative citations & \\
\hline $\begin{array}{l}\text { Constructing } \\
\text { learning } \\
\text { experiences }\end{array}$ & $\begin{array}{c}70 \\
(31 \%)\end{array}$ & $\begin{array}{l}\text { "Building games as a } \\
\text { means of learning... } \\
\text { increases } \\
\text { motivation and develops } \\
\text { creative problem-solving } \\
\text { skills. The children plan } \\
\text { their steps. They design, } \\
\text { test and improve their } \\
\text { artifacts." (T56) }\end{array}$ & $\begin{array}{c}13 \\
(9 \%)\end{array}$ & $\begin{array}{l}\text { "We basically started building a } \\
\text { robot with no sensors at all, a simple } \\
\text { card that had nothing and then I } \\
\text { added sensors, one at a time, and we } \\
\text { started working with it and talking } \\
\text { about it." } \\
\text { (T5) }\end{array}$ & -4.71 \\
\hline $\begin{array}{l}\text { Tinkering \& } \\
\text { debugging }\end{array}$ & $\begin{array}{c}55 \\
(25 \%)\end{array}$ & $\begin{array}{l}\text { "The Scratch environment } \\
\text { is very creative, user } \\
\text { friendly, and easy to } \\
\text { operate. Importantly, } \\
\text { students can try to create } \\
\text { codes over and over again, } \\
\text { until they succeed." (T7) }\end{array}$ & $\begin{array}{c}26 \\
(18 \%)\end{array}$ & $\begin{array}{l}\text { "I have a seventh grader who writes } \\
\text { very well-developed codes in } \\
\text { Scratch. For three lessons he was } \\
\text { trying to solve a problem and couldn't } \\
\text { figure out how to solve it. The design } \\
\text { was complex, and it didn't move } \\
\text { normally left to right. The student } \\
\text { resized the character and checked } \\
\text { with loops. Finally, I suggested } \\
\text { combining them." (T6) }\end{array}$ & tos \\
\hline $\begin{array}{l}\text { Collaborative } \\
\text { learning }\end{array}$ & $\begin{array}{c}22 \\
(10 \%)\end{array}$ & $\begin{array}{l}\text { "Above all, Scratch enables } \\
\text { collaboration, because it is } \\
\text { online, and the children } \\
\text { share their work. They can } \\
\text { learn from others, reuse and } \\
\text { refine their codes and thus, } \\
\text { the wisdom of the crowd } \\
\text { increases." (T1) }\end{array}$ & $\begin{array}{c}36 \\
(26 \%) \\
\end{array}$ & $\begin{array}{l}\text { "There are children who measure the } \\
\text { angles and children who are } \\
\text { responsible for programming. } \\
\text { Everyone does a part of the work. I } \\
\text { have a student with learning } \\
\text { disabilities, and it is very difficult for } \\
\text { him to do the programming, but he is } \\
\text { excellent in working with the robot } \\
\text { sensor. In this setting, everyone can } \\
\text { find his/her strength." (T11) }\end{array}$ & . \\
\hline
\end{tabular}




\begin{tabular}{|c|c|c|c|c|c|}
\hline Gamification & $\begin{array}{c}25 \\
(11 \%)\end{array}$ & $\begin{array}{l}\text { "Scratch allows students to } \\
\text { create their own artifacts by } \\
\text { playing. Incorporating play } \\
\text { into learning contributes to } \\
\text { student motivation and } \\
\text { enjoyment." (T10) }\end{array}$ & $\begin{array}{c}5 \\
(4 \%)\end{array}$ & $\begin{array}{l}\text { "What makes robotics unique is an } \\
\text { integration of gamification. I can } \\
\text { incorporate a game into learning and } \\
\text { students conduct the programming." } \\
\text { (T11) }\end{array}$ & -2.71 \\
\hline $\begin{array}{l}\text { Experiential } \\
\text { learning }\end{array}$ & $\begin{array}{c}21 \\
(9 \%)\end{array}$ & $\begin{array}{l}\text { "Learning with Scratch is } \\
\text { different from other } \\
\text { subjects. It is a more } \\
\text { enjoyable and experiential } \\
\text { way of learning...Students } \\
\text { enjoy and understand much } \\
\text { more through this kind of } \\
\text { learning." (T14) }\end{array}$ & $\begin{array}{c}46 \\
(32 \%)\end{array}$ & $\begin{array}{l}\text { "I let them think by themselves. I let } \\
\text { them experiment and reveal the code. } \\
\text { I don't write the code for them." (T9) }\end{array}$ & 9.23 \\
\hline $\begin{array}{l}\text { Examples } \\
\text { relevant } \\
\text { students }\end{array}$ & $\begin{array}{cc}22 \\
(10 \%)\end{array}$ & $\begin{array}{l}\text { "Nowadays, children learn } \\
\text { differently from how they } \\
\text { learned before. This } \\
\text { application helps me to } \\
\text { teach and connect better } \\
\text { with the children's world." } \\
\text { (T24) }\end{array}$ & $\begin{array}{c}2 \\
(1 \%)\end{array}$ & $\begin{array}{l}\text { "This application enables connecting } \\
\text { to the students' world and interests." } \\
\text { (T10) }\end{array}$ & -3.25 \\
\hline $\begin{array}{l}\text { Teacher's } \\
\text { explicit } \\
\text { instructions }\end{array}$ & $\begin{array}{c}8 \\
(4 \%)\end{array}$ & $\begin{array}{l}\text { "We teach them the basic } \\
\text { concepts of computer } \\
\text { science, adding sound tones } \\
\text { and audio files from the } \\
\text { software and from the } \\
\text { web." (T7) }\end{array}$ & $\begin{array}{c}15 \\
(10 \%)\end{array}$ & $\begin{array}{l}\text { "We start learning about a sensor and } \\
\text { then we connect it to a robot...First, I } \\
\text { explain what the idea beyond these } \\
\text { sensors is." (T5) }\end{array}$ & 3.88 \\
\hline $\begin{array}{l}\text { Total shared } \\
\text { category } \\
\text { statements }\end{array}$ & d 223 & & 143 & & \\
\hline
\end{tabular}


As can be seen from Table 1 the reflections immediately after the SPOC and the interviews after one year of teaching ECR curriculum revealed seven shared categories. However, the observed values of teacher statements from the interviews are significantly different from those expected based on the reflections. Raw residuals are the product of subtracting expected from observed values. A standardized residual was calculated by dividing the raw residual by the square root of the expected value as an estimate of the raw residual's standard deviation (Sharpe, 2015). The rule of thumb (Haberman, 1973) is that standardized cell residuals which exceed an absolute value of two (+/-2) are considered to contribute to a statistically significant degree in the omnibus chi-square test. It is promising that immediately after the training the participants had a significantly higher percentage of statements of constructing learning experiences, examples relevant to students, and gamification strategies. A year after teaching ECR curriculum, the teachers had a significantly higher percentage of statements reflecting experiential learning, collaborative learning, and teacher's explicit instructions strategies. Table 2 presents categories that emerged from teacher reflections or interviews. 
Table 2. Teaching strategies for ECR: Categories unique to either reflections or interviews

\begin{tabular}{|c|c|c|c|c|}
\hline & \multicolumn{2}{|r|}{ Reflections after the training course } & \multicolumn{2}{|r|}{ Interviews one year later } \\
\hline & $\begin{array}{c}\text { Codes } \\
(\%)\end{array}$ & Representative citations & $\begin{array}{c}\text { Codes } \\
(\%)\end{array}$ & Representative citations \\
\hline $\begin{array}{l}\text { Interdisciplinary } \\
\text { learning }\end{array}$ & 43 & $\begin{array}{l}\text { "Scratch contributes to students' } \\
\text { understanding of other subjects. } \\
\text { Example in math: Students get to } \\
\text { know geometric shapes, such as a } \\
\text { square and a triangle, and learn how } \\
\text { to calculate the angle of the polygon } \\
\text { with the aid of a robot." (T7) }\end{array}$ & -- & \\
\hline Assessment for learning & 2 & $\begin{array}{l}\text { "Students face the challenge of } \\
\text { applying the topic learned in the } \\
\text { classroom in their coding. Such tasks } \\
\text { can serve as an alternative assessment } \\
\text { and promote learning..." (T3) }\end{array}$ & -- & \\
\hline Peer to peer learning & -- & & 19 & $\begin{array}{l}\text { "When students ask for help, } \\
\text { first of all, I refer them to } \\
\text { another student. The idea is not } \\
\text { only to learn the material, but } \\
\text { also to acquire teamwork skills } \\
\text { and solve problems without } \\
\text { my involvement." (T5) }\end{array}$ \\
\hline $\begin{array}{l}\text { Allowing } \text { different } \\
\text { learning paths and } \\
\text { listening to student voice }\end{array}$ & -- & & 5 & $\begin{array}{l}\text { "Sometimes there is a situation } \\
\text { where each team does a } \\
\text { different project: one builds a } \\
\text { game, the other builds a } \\
\text { different game, and the third } \\
\text { makes a video or whatever. } \\
\text { Everyone does a different } \\
\text { thing...." (T8) }\end{array}$ \\
\hline $\begin{array}{l}\text { Total unshared } \\
\text { category statements }\end{array}$ & 45 & & 24 & \\
\hline $\begin{array}{l}\text { Total statements } \\
\text { (shared and unshared) }\end{array}$ & 268 & & 167 & \\
\hline
\end{tabular}


As can be seen in Table 2, immediately after the SPOC teachers reported two advanced pedagogical strategies - interdisciplinary learning and assessment for learning. After one year of teaching ECR curriculum they used even more advanced strategies, such as peer learning and teaching as well as allowing different learning paths and listening to student voice.

\section{The degree of teacher centrality in the classroom in code and robotic teaching}

In both reflections and interviews the data revealed four teaching prototypes with a different degree of centrality in the classroom: the teacher as a sage on the stage, as a facilitator, as a guide on the side, and as a learning partner. A chi-square goodness of fit test was significant: $X^{2}(3)=54.10, p=.000$. Standardized residuals are presented in Table 3. 
Table 3. Degree of teacher centrality in code and robotic lessons: reflections and interviews

\begin{tabular}{|c|c|c|c|c|c|}
\hline \multirow{2}{*}{$\begin{array}{l}\text { Categories } \\
\text { Teacher's } \\
\text { role }\end{array}$} & \multicolumn{2}{|r|}{ Reflections after the training course } & \multicolumn{2}{|r|}{ Interviews one year later } & \multirow{2}{*}{$\begin{array}{c}\text { Standardized } \\
\text { residual }\end{array}$} \\
\hline & $\begin{array}{c}\text { Codes } \\
(\%)\end{array}$ & Representative citations & $\begin{array}{c}\text { Codes } \\
(\%)\end{array}$ & Representative citations & \\
\hline $\begin{array}{l}\text { Sage-on- } \\
\text { the-stage }\end{array}$ & $\begin{array}{c}18 \\
(8 \%)\end{array}$ & $\begin{array}{l}\text { "By building games and robot } \\
\text { programming, you can teach a project } \\
\text { opening, project saving and change. You } \\
\text { can provide a series of instructions and } \\
\text { conduct an infinite repetition of variables } \\
\text { and calculations." (T12) }\end{array}$ & $\begin{array}{c}5 \\
(4 \%)\end{array}$ & $\begin{array}{l}\text { "Students understand rapidly because I show } \\
\text { them examples. Two weeks ago, I } \\
\text { demonstrated three options of scripts and } \\
\text { they worked accordingly. It was successful } \\
\text { and students were satisfied." (T2) }\end{array}$ & -.0 .92 \\
\hline Facilitator & $\begin{array}{c}131 \\
(56 \%)\end{array}$ & $\begin{array}{l}\text { "I prepared a tab that shows students how } \\
\text { to incorporate tone bricks ... I suggested } \\
\text { that they incorporate a "say" style brick, a } \\
\text { brick in which the child expresses his/her } \\
\text { opinion... In this way, they explore basic } \\
\text { concepts and acquire logical thinking." } \\
\text { (T40) }\end{array}$ & $\begin{array}{c}26 \\
(28 \%)\end{array}$ & $\begin{array}{l}\text { "The systematic and linear work develops } \\
\text { excellent work habits and skills in children. } \\
\text { When children were asked to create a round- } \\
\text { trip or back-and-forth action they } \\
\text { understood the meaning of minus (-), which } \\
\text { is usually learned in a math class as an } \\
\text { abstract concept. When students } \\
\text { experimented with the robot, it was after } \\
\text { experiencing such an action in animating } \\
\text { characters in the Scratch application." (T11) }\end{array}$ & -3.67 \\
\hline $\begin{array}{l}\text { Guide on } \\
\text { the side }\end{array}$ & $\begin{array}{c}76 \\
(32 \%)\end{array}$ & $\begin{array}{l}\text { "I arrange students in teams and it really } \\
\text { helps. Mostly I move between the groups. } \\
\text { I also choose some kids who are advanced } \\
\text { to help other kids.... They search for } \\
\text { solutions and stay motivated. The kids love } \\
\text { to learn this way (T49)." }\end{array}$ & $\begin{array}{c}49 \\
(53 \%)\end{array}$ & $\begin{array}{l}\text { "I don't feel like I'm transferring knowledge, } \\
\text { certainly not in robotics... I also say to the } \\
\text { kids: 'Just open a new tab, think if you have } \\
\text { a problem, and look for the solution.' I'm } \\
\text { their means for exposure to these new } \\
\text { things." (T2) }\end{array}$ & 3.45 \\
\hline Partner & $\begin{array}{c}8 \\
(4 \%)\end{array}$ & $\begin{array}{l}\text { "Scratch is very user friendly and } \\
\text { convenient to exploration by children. You } \\
\text { can easily start to design and encode. When } \\
\text { I encountered some challenges, I dealt with } \\
\text { them by letting the students find solutions. } \\
\text { They were able to find solutions fairly } \\
\text { quickly." (T52) }\end{array}$ & $\begin{array}{c}14 \\
(\mathbf{1 5 \%})\end{array}$ & $\begin{array}{l}\text { "When I started to teach ECR, I told them, 'I } \\
\text { am studying now as well. I started learning } \\
\text { shortly before you and I know just a little } \\
\text { more than you. So I have no problem with } \\
\text { making mistakes or not knowing something. } \\
\text { We can try to figure it out together.' " (T5) }\end{array}$ & 5.28 \\
\hline $\begin{array}{l}\text { Total } \\
\text { statements }\end{array}$ & 233 & & 94 & & \\
\hline
\end{tabular}


As can be seen, there was no significant difference between the measurements in the Sage on the stage category, probably because of the small number of participants in this category. However, the percentage of these very central-oriented teachers was twice as much immediately after the course. The teacher as a facilitator and opportunity creator in the reflection (one year after the training course) was 3.67 more in terms of the standardized residual than in the reflection. In contrast, the two contributing categories which got stronger a year later were teacher as a guide on the side, in which the observed frequency in the interviews was greater with 3.45 and teacher as a learning partner with a 5.28 standardized residual, than the expected frequency based on teacher reflections. It is promising that after teaching ECR for a year, the participants were able to release control and demonstrate a lower degree of centrality in their classroom.

\section{Teacher Professional Development in code and robotics via SPOC}

\section{SPOC benefits for TPD}

Teachers reported a variety of benefits $(\mathrm{N}=564$ statements) from the code robotics training course via the SPOC - immediately after the SPOC and one year after teaching the new curriculum in the classroom. At the end of the SPOC teachers reflected extensively on the advantages and disadvantages of learning by an online course. Four themes emerged from the data $(\mathrm{N}=503)$ : control dimensions $(256,51 \%)$, independent learning $(145,29 \%)$, learning and knowledge management $(86,17 \%)$, and collaboration $(16,3 \%)$. One year after teaching the new profession in the classroom, teacher interviews revealed the same dimensions regarding the SPOC contribution ( $\mathrm{N}=61)$ : independent learning $(32,52 \%)$, control dimensions $(17,28 \%)$, collaboration (7, 12\%), and learning and knowledge management (5, 8\%). Based on the findings of reflections and interviews, Figure 1 presents a model of the SPOC contribution for TPD, including both benefits and challenges, sub-categories that are detailed in the next sections. 


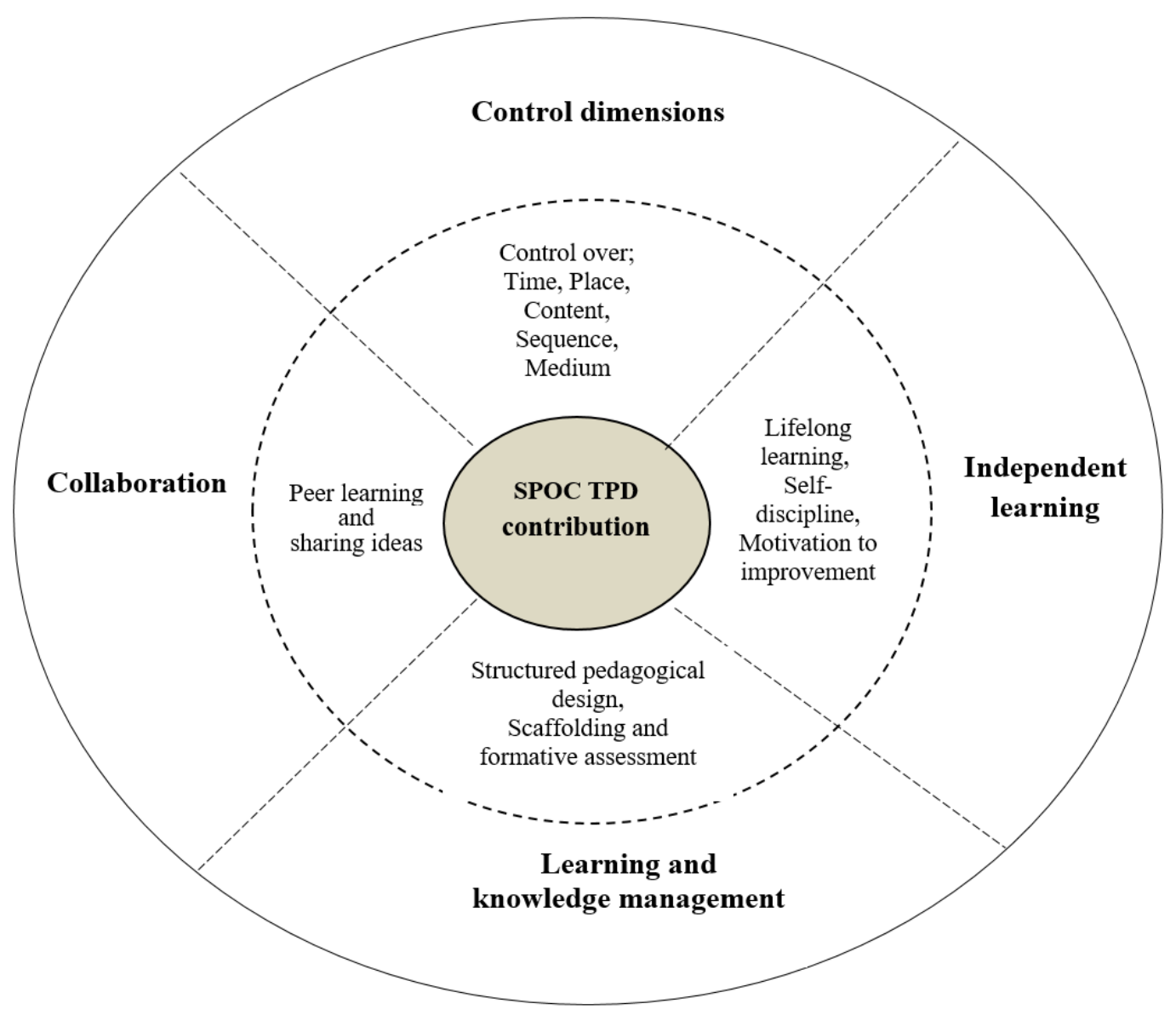

Figure 1. SPOC contribution to TPD: benefit and challenge categories

Control dimensions - Teachers reported a major number of statements related to the way they control and monitor their learning in the SPOC. Sub-categories included: control over time, place, content, sequence, and medium.

Control over time - Time was an important advantage in terms of teachers' self-regulated skills:

"Often people are not available to attend courses in face-to-face meetings due to... tight schedules. The SPOC enables them to acquire knowledge online at any time they want." (T14)

Control over place - Distance learning enables TPD for teachers who are unable to attend face-to-face:

"Since I live in a small remote village I enjoy the benefit of distance learning, which saves me much commuting time..." (T1).

Control over the content - refers to the ability to control the teaching/study session:

"I like learning online - you can always relearn the material if you feel that you didn't get it ..." (T15)

Control over the sequence - controlling sequence of the individual learning activities: 
"The SPOC was well-structured and allowed for step-by-step learning... One can move forward to skip what he already knows if he has confidence in accomplishing the task." (T13)

Control over the medium - refers to control over different channels of technological platforms:

"The way to study in the SPOC was interesting. Such an environment is multi-channel and media rich. I can listen to lectures, read articles, or watch videos that combine visuals with verbal explanations." (T43)

Independent learning- Teachers indicated the SPOC as an appropriate tool for self-directed and independent learning. Sub-categories that emerged from the data included: lifelong learning, self-discipline, and motivation for improvement.

Lifelong learning - refers to the capacity to use available resources for sustained learning processes and personal or professional development:

"Professional development is a necessary and very essential thing for my work as a teacher and mentor ...It makes no sense that the world and our students are changing, and schools remain behind". (T63)

Self-discipline - the responsibility for learning as an independent learner developer: "I am independent in my own learning and the SPOC suited me... A learner should motivate himself and develop personal responsibility for learning and self-discipline." (T1)

Motivation for improvement - the drive for development and change:

"I use every opportunity to attend teacher training. After studying in the course, I experienced professional improvement, innovation, and change, which always keep me relevant as a professional." (T12)

Learning and knowledge management - The pedagogical design of the SPOC and its formative assessment helped teachers manage their learning. Sub-categories which emerged from the data included structured pedagogical design, scaffolding, and formative assessment:

Structured pedagogical design - Teachers reported that the SPOC was a well-structured and organized course which helped them perform tasks and develop understanding and skills:

"The online course was very well structured and built from easy-to-complex concepts. It had a mix of videos with written explanations, summaries and refinements that were learned, and links to extensions." (T17)

Scaffolding and formative assessment - feedback as scaffolding for teacher learning:

"The instant opportunity to send learning outcomes and get feedback was exactly what I needed." (T56) 
Collaboration - Teachers reported that the course activities allowed them to work towards a common goal and offered various perspectives and external resources to generate solutions. Sub-categories of collaboration included peer learning and sharing ideas:

Peer learning: "I took the value of collaboration from this course. We constantly learned from each other how to solve a particular problem." (T32)

Sharing ideas: "...In terms of ideas, it was a large group, so there was always something to share. Participants always had ideas, especially ideas for learning activities. (T51)"

\section{SPOC challenges in TPD}

Alongside the benefits of code robotics TPD via the SPOC, some of the teacher statements $(\mathrm{N}=93)$ revealed challenges arising from the online nature of the course. Interestingly, in teacher reflections immediately after the SPOC, the same four themes that were presented as benefits of SPOC $(\mathrm{N}=87)$ emerged as challenges: knowledge management challenges (32, $36 \%)$, independent learning challenges $(29,33 \%)$, negative control dimensions $(24,26 \%)$, and lack of collaboration $(4,5 \%)$. In contrast, the interview data one year after teaching the new curriculum in the classroom reported very few statements $(\mathrm{N}=6)$ that reflected challenges of TPD via the SPOC.

Knowledge and learning management difficulties - Teachers reported difficulty in understanding the course structure and a lack of feedback that prevented them from successfully managing their learning: "When there was a question, it was not always addressed, and if it was, the answer was not immediate. There was no immediate (if any) feedback on task performance." (T14)

Independent learning difficulties - Teachers reported coping with the challenges of selfdirected learning, lack of self-discipline, and taking responsibility for learning:

"The main problem is the responsibility for learning. When you study face-to-face, you have a clear schedule of meetings (date, time). However, when learning is "in your hands", you are responsible for studying. In addition, you need to evaluate your progress. Teachers have a lot of ongoing work and sometimes tend to postpone the course study." (T21)

Negative control dimensions - Some of the teachers preferred training that takes place at a specific time and place. Moreover, there were teachers who reported online content overload: "The only challenge I encountered was time. In face-to-face TPD it is easier for me to get away from home chores, children, and family. When learning at home, I feel that I am not available to my family and children and, in addition, I postpone my duties as a homeroom teacher and ICT coordinator." (T78) 
Lack of collaboration - Teachers reported an insufficient level of peer learning during the course:

"A noticeable disadvantage of the course is the considerable time required for teamwork, since each teacher progresses at his or her own pace at home, and usually there is no possibility of brainstorming and learning from each other." (T19)

\section{Discussion}

This study explores pedagogical strategies prevalent in ECR learning: the degree of teacher centrality in the ECR classroom and the added value of the SPOC for professional training of ECR teachers. These aims were examined through reflections immediately after their training in ECR via the SPOC and through interviews with some of these teachers one year after teaching ECR in the classroom.

The first research questions explored pedagogical strategies prevalent in ECR teaching. ECR is a new curriculum aiming to develop computational thinking and promote creativity, collaboration, problem-solving, and self-expression as well as student motivation and self-confidence (Blau \& Benolol, 2016; Chen et al., 2020; García-Peñalvo et al., 2016; Scherer et al., 2018; Zviel-Girshin, 2020). Seven pedagogical strategies in ECR teaching were found in both participant reflections and interviews: constructing learning experiences, tinkering \& debugging, collaborative learning, gamification, experiential learning, examples relevant to students, and teacher's explicit instructions. Among these strategies, immediately after the TPD the most prevalent were constructing learning experiences and tinkering \& debugging, which was one of the crucial CT skills highlighted during the TPD. After a year of teaching there were more prevalent strategies which worked well in the ECR classroom experiential learning and collaborative learning, while the next most common strategy again was tinkering \& debugging. Developing CT skills is the ultimate goal of ECR (Chen et al., 2017). Consistent with the prevalence of experiential learning and collaborative learning in our findings, CT is not the idea of being technology-savvy, but rather using computational methods to solve complex problems in teams (Romero, Lepage \& Lille, 2017; Yadav et al., 2016). As teacher T11 reflected: "...Everyone in the team does a part of the work to move the project forward ... In this setting, everyone can find and use his/her strength."

In addition to the seven shared strategies that appeared both in reflections and interviews, teachers also spoke about interdisciplinary learning and in a few cases referred to assessment for learning in their reflections. After one year of teaching ECR, teachers reported using even 
more advanced pedagogical strategies, such as peer learning and teaching and in some cases allowing different learning path and listening to student voice. These findings further support previous studies, which emphasized that CT and problem-solving ability requires teamwork skills and experimental learning experience (Chen et al., 2020; Hsu et al., 2018; Romero et al., 2017; Sentance \& Csizmadia, 2015). However, after one year in the classroom teachers used fewer examples related to students' world. Instead, they preferred to provide explicit instructions that served as a start for experiential learning and/or teamwork: "...I tell them what this code does... They experiment to find the code. I don't help them beyond this." (T9). Thus, it seems that teachers in this study were combining various strategies, both basic and advanced, which eventually led students to develop proficiency. These findings are consistent with previous research emphasizing the need to employ different teaching strategies and methods in order to adjust learning to the level of different students and develop their computational thinking skills (Denning, 2017; Tozadore \& Romero, 2020).

Notably, gamification strategy, using game design elements to improve student engagement, motivation, and performance (Hamari, Koivisto \& Sarsa, 2014; Khandelwal, Sripada \& Reddy, 2017), was no longer a prevalent strategy after a year of teaching ECR. This finding can be explained by previous research (Gumennykova et al., 2019), which emphasized that in ECR the automatic control of robots per se is already considered as a game process and thus, was not perceived by our participants as a teaching strategy. An alternative explanation could be that in an educational setting the primary goal is to enhance learning, improve the quality of the code, and increase student engagement rather than gamification (Khandelwal et al., 2017).

\section{The second aim of the study was to reveal the degree of teacher centrality in the} classroom in ECR. Teachers, both in reflections and interviews, revealed four teaching prototypes reflecting different degrees of centrality in the classroom: teacher as a sage on the stage, facilitator, guide on the side, and learning partner. These four prototypes are consistent with Yondler and colleagues' (2018) model and partially overlap with Grasha and YangarberHicks' (2000) framework.

The main pattern that occurred during the first year of teaching ECR was a step towards lower teacher centrality in the classroom. The most frequent category after the training (more than half of the statements) reflected facilitator as the teacher's role in the classroom, while after one year of teaching ECR, more than half of the participants' statements reflected the guide on the side role. The facilitator is a teacher who helps students construct their knowledge 
by providing directions and well-structured opportunities for exploration (Grasha \& Yangarber-Hicks, 2000; Yondler et al., 2018). In contrast, the teacher as a guide on the side supports and encourages student exploration in an open-ended manner in order to develop students as autonomous and self-directed learners (Grasha \& Yangarber-Hicks, 2000; Yondler et al., 2018). This is reflected in the teacher T2 quote: "... They don't need me for conveying information... I mostly guide them in exploration of new ways of coding...".

Similarly, the least frequent category after the training was learning partner, while after a year in the classroom it was sage-on-the-stage. Sage-on-the-stage is a teacher with the highest degree of centrality in the classroom who provides "right" answers and explicit "do" and "do not" instructions (Yondler et al., 2018). It is not surprising that this teaching style was found in the present study and previous research as the least appropriate for constructionist learning in technology-enhanced settings such as ECR (Basogain et al., 2016; Author3 et al., 2019; Chen et al., 2020). In contrast, the teacher as a learning partner is a teacher with the lowest degree of centrality in the classroom, who not only provides opportunities for students to construct knowledge on their own while actively experimenting in the digital space, but also feels comfortable to learn with students and even from them (Yondler et al., 2018). Similarly, other studies in ECR teaching suggest involving students as co-design partners in the learning process (Basogain et al., 2016; Chen et al., 2020). Our findings reinforce the literature regarding teachers who, by embracing the partner role in technology-enhanced learning environments, support cognitive and emotional aspects of students' learning (Author3 et al., 2019; Chen et al, 2020; Hsu et al., 2018; Tozadore \& Romero, 2020).

\section{The final aim of the study was to reveal the added value of a SPOC for distance teacher}

training. Regarding the contribution of the SPOC for TPD, teacher statements revealed significantly more benefits than challenges (564 and 93 respectively). The proportion of benefit and challenge statements was similar in reflections immediately after the SPOC (503 and 61 respectively) and in the interviews one year later (87 and 6 respectively). Interestingly, the same categories emerged from the data as both benefits and challenges.

After experiencing self-directed learning in the SPOC during TPD, teachers reported numerous statements relating to a variety of control dimensions mentioned as both positive and negative of the online course. Some of the control dimensions referred to control over time - when to study (e.g. which days, what time of the day) - and for how long (e.g. shorter or longer study sessions). Other statements referred to control over place, - enabling 
geographically dispersed teachers who are unable to attend face-to-face training to participate in online training through the SPOC, as well as to control where to study - at home, during commute, or in the workplace. The possibility to learn at his/her pace makes participation in a SPOC suitable for the wide audience (Kaplan \& Haenlein, 2016). In addition, teachers referred to control over the course content - their control over decisions of whether to attend the lecture or to move to more or less advanced learning content. Another advantage is the ability to have control over the sequence of learning activities. A SPOC enables them to decide regarding the order of learning activities - whether to repeat or skip learning components. The last dimension addressed the teachers' ability to have control over the medium. The SPOC is a digital multichannel environment that includes features such as video lectures, assessments, interactive labs, and discussion forums. Teachers in the current and previous studies have demonstrated the ability to cope with these digital learning environments (Fu, 2019; Kaplan \& Haenlein, 2016; Marcelino et al., 2018). Distance learning via an online course allows flexibility, promotes independent learning, and eventually develops self-regulation skills. Models of self-regulation propose that the control aspect is one of the important targets of regulation, which encompasses cognitive, emotional, and behavioral control (Gross, 2014; Nigg, 2017). Despite these benefits, some of our participants reported challenges of controlling the characteristics of the online course and expressed preference for face-to-face learning at a specific time and place.

Regarding the continuity of the control dimensions, consistent with previous studies $(\mathrm{Fu}$, 2019; Koukis \& Jimoyiannis, 2019; Toikkanen \& Leinonen, 2017), teachers in this study indicated that the SPOC provided opportunities for self-directed and independent learning. Teachers perceived themselves as lifelong learners capable of using it as a means to improve the quality of their lives (Derrick, 2003). Teachers showed a strong drive for self-development and motivation to improve their performance as learners. As one of the teachers summarized: "I am independent in my learning and the SPOC suited me... A learner should motivate himself and develop personal responsibility for learning and self-discipline." (T1). This is consistent with previous findings that a SPOC requires a relatively high level of intrinsic motivation and self-discipline (Kaplan \& Haenlein, 2016). Online courses demand a high level of engagement and taking responsibility for the learning process (Blau \& Shamir-Inbal, 2018; Koukis \& Jimoyiannis, 2019), demands that some of the teachers in the current study found to be difficult to cope with. 
Another advantage of the SPOC is the ability to manage learning and knowledge through the SPOC. Learning and knowledge management - assimilating new information, generating new knowledge and putting knowledge into practice - are important skills in the digital age (Thomas, Sussman \& Henderson, 2001). Teachers saw great importance in the SPOC structured pedagogical design and the formative assessment, which greatly helped to develop their learning management skills. However, some of the teachers reported difficulties in managing their learning. TPD through a SPOC includes asynchronous activities in addition to the synchronous sessions. Asynchronous and well-structured and designed SPOCs provide full control over when and how to learn and tend to work better than synchronous sessions (Kaplan \& Haenlein, 2016). Consistent with previous findings, the more control participants have over their environment, the more successful they tend to be in managing their learning (Kaplan $\&$ Haenlein, 2016; Toikkanen \& Leinonen, 2017).

The last categories which emerged from the teacher responses were collaboration and peer learning. These categories, which were found to be the important strategies for teaching ECR, also emerged as an important advantage of the SPOC. Online structured courses allow participants to work toward a common goal and offer various perspectives and external resources to generate solutions. As a teacher (T32) indicated: “...if one coordinator couldn't solve a particular problem, we helped each other." Unfortunately, a few of the participants expressed dissatisfaction from a lack of collaboration. According to these findings, and consistent with prior studies (Blau \& Shamir-Inbal, 2018; Koukis \& Jimoyiannis, 2019), it can be argued that deeper engagement can be achieved by an ongoing dialogue in a course learning community with peer facilitation, collaboration on learning processes and outcomes, and embedded self- and peer-assessment.

\section{Conclusion, limitations and educational implications}

This study examined the added value of TPD via a SPOC. Recently, distance learning has been shown to be essential for both teachers and students because of workloads or situations such as the COVID-19 pandemic. However, very few studies examined teacher training through online courses. Therefore, our aim was to create an evidence-based model of TPD via a SPOC, which clarifies both benefits and challenges revealed by teachers.

Based on our findings, we can suggest the SPOC as a legitimate alternative to face-to-face TPD. In order to promote skills such as collaboration, independent learning, and tinkering skills among their students, teachers must experience self-directed learning themselves during their 
training (Koukis \& Jimoyiannis, 2019). This study's findings suggest that a SPOC offers teachers the opportunity to experience independent work and the way of managing learning processes in a digital environment. The findings highlight the importance of strategies such as dialogues in a course learning community, peer facilitation, and collaboration for learning processes and outcomes in order to increase trainee engagement and self-regulation. However, as revealed in current research and prior studies, a SPOC requires a relatively high level of intrinsic motivation and self-discipline, therefore the SPOC is recommended primarily as a way to build new skills in order to strengthen an existing professional career (Kaplan \& Haenlein, 2016).

This study suggests that understanding the core elements of ECR would enable teachers to integrate the program into the curriculum. Moreover, by integrating the appropriate strategies and providing guidance, teachers allowed students to develop 'computational thinking' competencies. Therefore, one of the aims of this study was to embed the teachers' perspective into a comprehensive understanding that sheds light on a pedagogical approach which includes strategies and teaching methods for educational code and robotic learning.

Our findings raise a number of implications for teachers of ECR. First, teachers need to support and encourage students to function as autonomous and self-directed learners. In addition, we recommend that teachers allow students to explore different learning paths in their code and robotic learning. Students must creatively experiment with code and robotics along with collaboration and peer learning.

This work was the initial and essential step toward an exploration of new ways of online teacher training as an alternative to face-to-face TPD. Although the conclusions are based on a very large amount of qualitative data collected in two time points (1,091 statements from the reflections of 80 trainees and 328 from the interviews with 13 ECR teachers conducted a year later), it should be taken into consideration that this study was based on self-reported methodology. Further studies may crosscheck teachers' perspectives with observations on learning and teaching in the classroom. In addition, this study examined one course of code and robotics. Future studies could examine courses in different disciplines with diverse pedagogical designs. It would be interesting to expand the research by examining students' strategies of learning in the ECR classroom and also to understand whether their strategies differ according to the role the teacher plays in the classroom. 


\section{References}

Agresti, A. (2018). An introduction to categorical data analysis. (3 $3^{\text {rd }}$ ed.). John Wiley \& Sons, 39-42.

Baek, Y., Wang, S., Yang, D., Ching, Y. H., Swanson, S., \& Chittoori, B. (2019). Revisiting Second Graders' Robotics with an Understand/Use-Modify-Create (U 2 MC) Strategy. European Journal of STEM Education, 4(1), 7.

Basogain, X., Olabe, M. A., C., O. J., Ramírez, R., \& García, J. (2016). PC-01: Introduction to Computational Thinking. Educational Technology in Primary and Secondary Education. In F. J. García-Peñalvo \& J. A. Mendes (Eds.), XVIII Simposio Internacional de Informática Educativa, SIIE 2016 (pp. 191-195). Salamanca, España: Ediciones Universidad de Salamanca.

Blau, I., \& Benolol, N. (2016). Can designing self-representations through creative computing promote an incremental view of intelligence and enhance creativity among atrisk youth? Interdisciplinary Journal of e-Skills and Lifelong Learning, 12, 267-278.

Blau, I., \& Shamir-Inbal, T. (2018). Digital technologies for promoting "student voice" and co-creating learning experience in an academic course. Instructional Science, 46 (2), 315-336.

Blau, I., Shamir-Inbal, T. \& Malka. A. (2019). How we teach digital literacy in formal education: The gap between teachers' perspectives and actual educational practices in the classroom. In Proceedings of the Knowledge Management Conference-KM 2019- Knowledge Management: Research, Organization, and Applied Innovation. Warsaw, Poland.

Cengel, M., Alkan, A., \& Cayir, E. (2018). In the Determination of Self-Efficacy Situations of Information Technology Teachers' Coding for Middle School Students, Robotic Coding and 3 Dimensional Design Examples of Sakarya Province. Online Submission.

Chen, H., Park, H. W., \& Breazeal, C. (2020). Teaching and learning with children: Impact of reciprocal peer learning with a social robot on children's learning and emotive engagement. Computers \& Education, 150, 103836.

Chen, G., Shen, J., Barth-Cohen, L., Jiang, S., Huang, X., \& Eltoukhy, M. (2017). Assessing elementary students' computational thinking in everyday reasoning and robotics programming. Computers \& Education, 109, 162-175.

Denning, P. J. (2017). Remaining trouble spots with computational thinking. Communications of the ACM, 60(6), 33-39.

Derrick, M. G. (2003). Creating environments conducive for lifelong learning. New directions for adult and continuing education, 2003(100), 5-18.

Fu, Y. (2019). A "Maker Education+ SPOC" Teaching Model for College Political Economics Courses. International Journal of Emerging Technologies in Learning (iJET), 14(03), 139-150.

Gabriele, L., Bertacchini, F., Tavernise, A., Vaca-Cárdenas, L., Pantano, P., \& Bilotta, E. (2019). Lesson Planning by Computational Thinking Skills in Italian Pre-Service Teachers. Informatics in Education, 18(1), 69-104.

García-Peñalvo, F. J., Reimann, D., Tuul, M., Rees, A. M., \& Jormanainen, I. (2016). TACCLE 3, O5: An overview of the most relevant literature on coding and computational thinking with emphasis on the relevant issues for teachers. Belgium. doi: https://doi. org/10.5281/zenodo, 165123 .

Grasha, A. F., \& Yangarber-Hicks, N. (2000). Integrating teaching styles and learning styles with instructional technology. College teaching, 48(1), 2-10.

Gross, J.J. (2014). Emotion regulation: Conceptual and empirical foundations. Handbook of Emotion Regulation, 2, 3-20.

Gumennykova, T. P., Blazhko, O. A., Luhova, T. A., Troianovska, Y. L., Melnyk, S. P., \& Riashchenko, O. I. (2019). Gamification features of STREAM-education components with education robotics. Applied aspects of information technology, (2, no 1), 45-65.

Haberman, S. J. (1973). The analysis of residuals in crossclassified tables. Biometrics, 29, 205-220. doi.org/10.2307/2529686 
Hamari, J., Koivisto, J., \& Sarsa, H. (2014, January). Does gamification work?--a literature review of empirical studies on gamification. In 2014 47th Hawaii international conference on system sciences (pp. 3025-3034). Ieee.

Heitink, M., Voogt, J., Verplanken, L., van Braak, J., \& Fisser, P. (2016). Teachers' professional reasoning about their pedagogical use of technology. Computers \& education, 101, 70-83.

Hsu, T. C., Chang, S. C., \& Hung, Y. T. (2018). How to learn and how to teach computational thinking: Suggestions based on a review of the literature. Computers \& Education, 126, 296-310.

Kalelioglu, F., Gulbahar, Y., \& Kukul, V. (2016). A framework for computational thinking based on a systematic research review. Baltic Journal of Modern Computing, 4(3), 583- 596.

Kaplan, A. M., \& Haenlein, M. (2016). Higher education and the digital revolution: About MOOCs, SPOCs, social media, and the Cookie Monster. Business Horizons, 59(4), 441-450.

Kappas, S., \& Tsolis, D. (2018). Greek University MOOCs and Secondary Education Teachers' Training. International Journal of Learning, Teaching and Educational Research, 17(5), 26-46.

Khandelwal, S., Sripada, S. K., \& Reddy, Y. R. (2017, February). Impact of gamification on code review process: An experimental study. In Proceedings of the 10th Innovations in Software Engineering Conference (pp. 122-126).

Koukis, N., \& Jimoyiannis, A. (2019, November). Investigating Participants' Collaborative Patterns in a MOOC for Teacher Professional Development. In European Conference on e-Learning (pp. 303-312). Academic Conferences International Limited.

Kvale, Steinar (1983). The qualitative research interview: A phenomenological and a hermeneutical mode of understanding. Journal of Phenomenological Psychology, 14, 171-196.

Lincoln Y.S. \& Guba E.G. (1985). Naturalistic Enquiry. Sage Publi-cations, Thousand Oaks, CA.

Marcelino, M. J., Pessoa, T., Vieira, C., Salvador, T., \& Mendes, A. J. (2018). Learning computational thinking and scratch at distance. Computers in Human Behavior, 80, 470-477.

Mason, S. L., \& Rich, P. J. (2019). Preparing elementary school teachers to teach computing, coding, and computational thinking. Contemporary Issues in Technology and Teacher Education, 19(4), 790-824.

Ministry of Education. (2016). Computer Science and Robotics Program. (Hebrew). Retrieved October 16, 2020 from: https://sites.education.gov.il/cloud/home/machshev robotika/Pages/kol kore robotika.aspx

Nigg, J. T. (2017). Annual Research Review: On the relations among self-regulation, self-control, executive functioning, effortful control, cognitive control, impulsivity, risk-taking, and inhibition for developmental psychopathology. Journal of child psychology and psychiatry, 58(4), 361-383.

Oliver, D. G., Serovich, J. M., \& Mason, T. L. (2005). Constraints and opportunities with interview transcription: Towards reflection in qualitative research. Social forces, 84(2), 1273-1289.

Rodgers, C. (2002). Defining reflection: Another look at John Dewey and reflective thinking. Teachers college record, 104(4), 842-866.

Romero, M., Lepage, A., \& Lille, B. (2017). Computational thinking development through creative programming in higher education. International Journal of Educational Technology in Higher Education, 14(1), 42.

Scaradozzi, D., Screpanti, L., Cesaretti, L., Storti, M., \& Mazzieri, E. (2019). Implementation and assessment methodologies of teachers' training courses for STEM activities. Technology, Knowledge and Learning, 24(2), 247-268.

Scherer, R., Siddiq, F., \& Viveros, B. S. (2018). Technology and the Mind: Does Learning to Code Improve Cognitive Skills?. In Proceedings of the Technology, Mind, and Society (pp. 1-1).

Sentance, S., \& Csizmadia, A. (2015, June). Teachers' perspectives on successful strategies for teaching Computing in school. In IFIP TCS.

Selby, C. C., \& Woollard, J. (2013). Computational thinking: The developing definition. In Presented at the 18th annual conference on innovation and Technology in Computer Science Education, Canterbury. 
Sharpe, D. (2015). Chi-Square Test is Statistically Significant: Now What?. Practical Assessment, Research, and Evaluation, 20(1), 8.

Tang, Y., Hua, C., Li, J., Li, M., \& Mao, P. (2019). On the Construction of SPOC Curriculum in Applied Technology University.

Toikkanen, T., \& Leinonen, T. (2017). The code ABC SPOC: Experiences from a coding and computational thinking SPOC for Finnish primary school teachers. In Emerging research, practice, and policy on computational thinking (pp. 239-248). Springer, Cham.

Thomas, J. B., Sussman, S. W., \& Henderson, J. C. (2001). Understanding "strategic learning": Linking organizational learning, knowledge management, and sensemaking. Organization science, 12(3), $331-345$

Tozadore, D. C., \& Romero, R. A. F. (2020). Graphical User Interface for educational content programming with social robots activities and how teachers may perceive it. Revista Brasileira de Informática na Educação, 28, 191.

Wang, X. H., Wang, J. P., Wen, F. J., Wang, J., \& Tao, J. Q. (2016). Exploration and Practice of Blended Teaching Model Based Flipped Classroom and SPOC in Higher University. Journal of Education and Practice, 7(10), 99-104.

Wing, J. M. (2008). Computational thinking and thinking about computing. Philosophical Transactions of the Royal Society of London A: Mathematical, Physical and Engineering Sciences, 366(1881), 3717-3725.

Yadav, A., Hong, H., \& Stephenson, C. (2016). Computational thinking for all: pedagogical approaches to embedding 21 st century problem solving in K-12 classrooms. TechTrends, 60(6), 565-568.

YYY, Author3, BBB, \& EEE (2018).

Yondler, Y., Blau, I., Ben-Yehudah, G., \& Eshet-Alkalai, Y. (2018). Different but equally effective? Four models for technology-enhanced optimal teaching of digital literacy skills. In Proceedings of the EARLI - Instructional Design \& Educational Technology Meeting: Instructional Design and Technology for 21st Century Learning: Challenges, Solutions, and Future Directions. Bonn, Germany.

Zviel-Girshin, R., Luria, A., \& Shaham, C. (2020). Robotics as a Tool to Enhance Technological Thinking in Early Childhood. Journal of Science Education and Technology, 1-9. 